\title{
A social work study on measuring the impact of government subsidies reform on economy
}

\author{
Mohammad Reza Iravani $^{\mathrm{a}^{*}}$, Behrooz Rodbaraki Kelari ${ }^{\mathrm{b}}$, FaezehTaghipour ${ }^{\mathrm{c}}$ and Gholamreza \\ Tajbakhsh $^{\mathrm{d}}$
}

\author{
${ }^{a}$ Department of Social Work, Islamic Azad University of Khomeinishahr, Khomeinishahr Branch, Daneshjou Blvd, Iran \\ ${ }^{b}$ Yerevan State University, Faculty of Ethnography \\ ${ }^{c}$ Assistant Professor, Department of Cultural Management Khorasgan (Isfahan) Branch, Islamic Azad University, Isfahan, Iran \\ ${ }^{d}$ Assistant Professor of Sociology Grand Ayatollah Boroujerd, Iran
}

\section{A R T I C L E I N F O \\ A B S T R A C T}

Article history:

Received June 29, 2012

Received in Revised form

August, 19, 2012

Accepted 17 September 2012

Available online

September 192012

Keywords:

Government subsidies

Economic reform

Unemployment

Inflation

\begin{abstract}
Government subsidies have been a major concern in many developing countries and they could create major problems such as increase in smuggling, lack of interest in investment, etc. During the past couple of years, the government of Iran decided to eliminate subsidies in different goods such as energy prices and food. In this paper, we present a survey to measure the impacts of such deregulation on Iranian economic factors including inflation, unemployment, tuition fee, consumer consumption pattern and city transportation facilities. The survey distributes a questionnaire among 51 university students aged 20 to 26 in Likert scale. We have used Pearson correlation test to study the relationship between deregulation on government subsidies and other mentioned factors. The results of the survey indicate that there is a meaningful relationship between government subsidies and unemployment, transportation facilities, consumer consumption pattern. However, the survey does not find sufficient evidence to believe that there is any relationship between government subsidies and inflation, increase in tuition fee.
\end{abstract}

\section{Introduction}

For years, most governments have offered subsidies to favored groups as a partial solution to their national housing crisis. There are literally various forms of subsidies from public housing and income tax relief on mortgage payments encouraging poor people to invade public land. Gradually, subsidies for housing have become less important but one form, targeted capital subsidy schemes, is recently getting used in several poor countries (Gilbert, 2012). Shin and Kim (2010), for instance, studied the effect of subsidy policies on the product quality improvement. They analyzed the impact of government subsidy policies on creating an incentive for domestic firms to increase their product quality before exporting to an outside market. The objective of the government was to minimize the time it takes to reach the appropriate product quality level at low costs. They concluded that there was an optimal combination between the subsidy and the time limits.

\footnotetext{
* Corresponding author. Tel: +989130758065

E-mail addresses: iravani@iaukhsh.ac.ir (M. R. Irvani) 
Research and development projects (R\&D) normally need substantial investment and may fail in practice. Therefore, many governments help this sector by providing subsidies (Blanes \& Busom, 2004). Kleer (2010) investigated government $R \& D$ subsidies as a signal for private investors. He explained that government subsidies for $R \& D$ could be intended to promote projects with high returns to society but too little private returns to be beneficial for private sectors but this could be caused by spillovers. They used a simple signaling model with various kinds of R\&D projects to capture this phenomenon.

The recent increase in oil prices, however, has increased motivation among governments of most Middle East countries to think about removing energy subsidies mostly in an attempt to reduce energy smuggling and consumer consumption. There are different studies associated with energy subsidies in the world. Deregulation on subsidies could have indirect impact on goods and services.

Badcock and Lenzen (2010) presented estimates of the extent of subsidization globally for various electricity-generating technologies including coal-fired, nuclear, wind, solar PV, concentrating solar, geothermal, biomass and hydroelectric power. Their survey permitted a comparison of subsidies for electricity-generating technologies, based on the respective states of development and deployment during various time periods. The survey indicated that hydropower received the least subsidies per unit of electricity and geothermal and nuclear power receive an equally low level of subsidies per $\mathrm{kWh}$ generated. They also mentioned that, amongst renewables, wind power had registered a spectacular success story in reducing the need for subsidization. The same does not hold for the two solar technologies, and for biomass.

Coal-fired power has the highest subsidization level, despite its high level of global deployment, which is mainly due to climate change effects. The study also demonstrated that accounting for subsidies under an agreed framework could play important role for informing future policy decisions on subsidization.

Liu and Li (2011) discussed that fossil energy subsidies reform could be a good tool to improve the energy consumption structure; but they argued that the reform required to be considered, carefully. They implemented price-gap technique to estimate the fossil energy subsidies of China and built computable general equilibrium (CGE) framework, which contains pollutant emissions accounts and $\mathrm{CO}_{2}$ emissions account to stimulate the fossil energy subsidies reform under various scenarios. Besides, they investigated the possibility of improving the energy consumption structure from the perspective of technical and economic analysis. Their results indicated that the energy consumption structure could be improved by various extents by removing coal or oil subsidies, while the economic and social indexes could be impacted, distinctively. Meanwhile, the impacts of cutting coal subsidies were more feasible than that of cutting oil subsidies overall.

Lin and Jiang (2011) performed an investigation for estimation of energy subsidies in China and impact of energy subsidy reform. Their findings indicated that removing energy subsidies would result in a substantial fall in energy demand and emissions, but could have negative effect on macroeconomic variables. They also reported that offsetting policies could be adopted such that certain shares of these subsidies were reallocated to support other sustainable development measures, which yield reduction in energy intensity and favoring the environment.

The food subsidy programs and its long-term impacts have emerged as major developmental issues in different developing countries. The programs normally increase social welfare to individuals but they could also pose both an unnecessary burden on the public budget and are economically inefficient. Karami et al. (2012) investigated the impacts of alternative food subsidy reforms on households' welfare and government cost in Iran. They used CGE, by considering gradual omission of subsidy during 3 and 5 years period and immediate complete omission of food subsidy. The results stated that in these polices government cost decreased by $5.8 \%$, and there was a decrease in import and export of agricultural and non-agricultural goods, but decreases in import exceeds the export reduction. The 
results also showed that the welfare of households' decreases for all scenarios, since decreases in urban households was greater than as rural households. They recommended to implement the food subsidy reform in 5 years period to lower income segments of the society.

Sadeghi and Ameli (2012) presented the implementation of a multi criteria decision making called analytical hierarchy process (AHP) decision model for sectoral allocation of energy subsidy. With determination of priorities for these criteria through questionnaire and AHP method, the overall rank of these criteria, which would have the most impact on distribution of energy subsidy among socioeconomic sub-sectors. The results indicated that inflation, economic growth, labor intensity, distribution of energy subsidy among socio-economic levels, energy intensity and social cost of air pollution are the most important factors. According to the model, the first priority for allocation of energy subsidy is commercial sector and the last priority is associated with transportation sector. Investigating the effect of changing priority of the criteria on overall results indicated that the socioeconomic sub sectors' ranking in receiving subsidy had little sensitivity for changing priority of the subsidy criteria.

Obeng and Sakano (2008) studied total factor productivity decomposition when firms receive both operating and capital subsidies. The resulted of their studies indicated that older works considered either the lump-sum or substitution impacts of these subsidies but not together. They found that the lump-sum impacts of the subsidies could reduce total factor productivity more than does the substitution impact.

Gupta and Mukherjee (2012) performed an investigation to realize whether the subsidy given to CSTC, which is the oldest and the largest state transport corporation operating in and around Kolkata, was being used to cover the losses they had made in the past or to simply cover-up an ineffective performance. The study concluded that the subsidy given was not based on any of the components on which it should, economically.

Hao et al. (2009) established the game model among the income of residents, enterprises operating costs, and subsidies through utility theory. The survey demonstrated the benefits of classification subsidy of public transit riders and established a specific operable subsidy calculating framework. Then, the calculation of Beijing public transit subsidies in 2007 was considered as a case study. The results showed that the subsidy classification and the subsidy calculating model not only could fully satisfy the travel demands of public transit riders but also it could efficiently calculate the subsidy amount, which realized the utility maximization of government subsidy.

The proposed study of this paper presents a survey to measure the impacts of deregulation on Iranian economic factors including inflation, unemployment, tuition fee, consumer consumption pattern and city transportation facilities. The organization of this paper first presents problem statement in section 2 and details of our results are given in section 3. Finally, concluding remarks are given in the last to summarize the contribution of the paper.

\section{The proposed study}

The proposed study of this paper measures the impacts of such deregulation on Iranian economic factors including inflation, unemployment, tuition fee, consumer consumption pattern and city transportation facilities. The survey distributes a questionnaire among 51 university students aged 20 to 26 in Likert scale. We have used Pearson correlation test to study the relationship between deregulation on government subsidies and other mentioned factors. Fig. 1 shows distribution of their ages. 


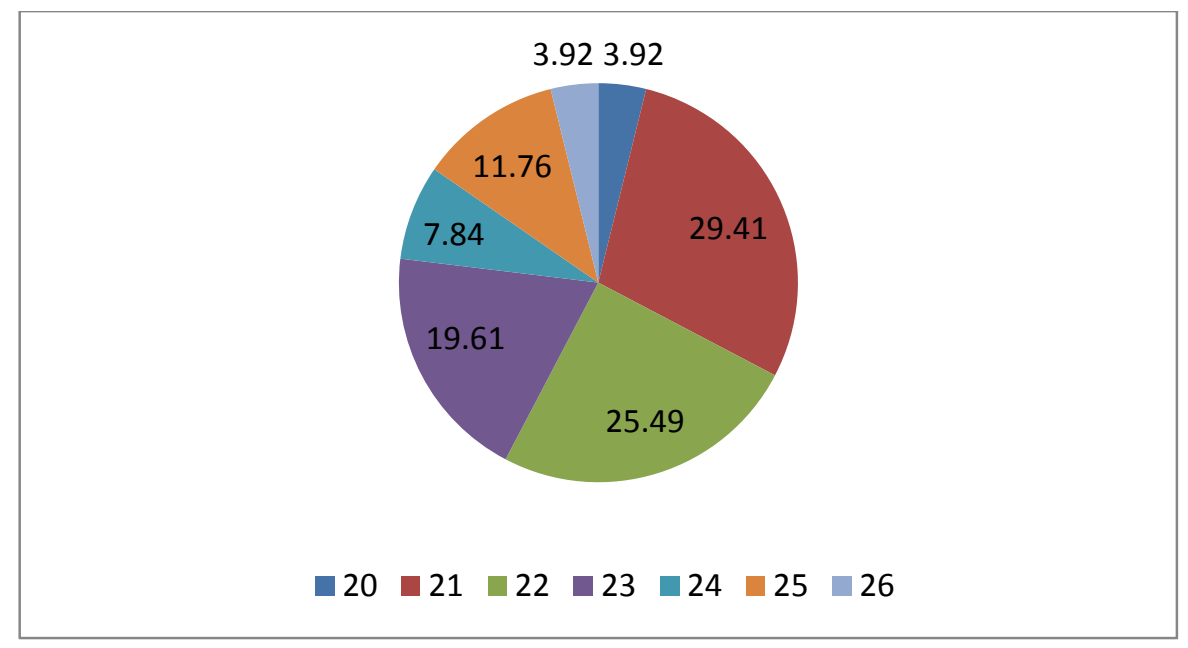

Fig. 1. Distribution of participants in terms of their age

As we can observe from the figure, most of the participants were between 21 to 23 years old and they were attending university educations. In fact, $37.3 \%$ of the participants were studying social science, $25.5 \%$ of the participants were attending government management program, $17.6 \%$ were studying economics and $19.7 \%$ of the participant were enrolled in psychology. In terms of income, nearly $84.3 \%$ of the participants did not have any job and the rest of them had small amount of income. The proposed study of this paper as considered the following five hypotheses,

\subsection{Unemployment and subsidies}

$\mathrm{H}_{0}$ : There is no meaningful relationship between unemployment and subsidies elimination.

$\mathrm{H}_{1}$ : There is a meaningful relationship between unemployment and subsidies elimination.

\subsection{Inflation and subsidies}

$\mathrm{H}_{0}$ : There is no meaningful relationship between subsidies and subsidies elimination.

$\mathrm{H}_{1}$ : There is a meaningful relationship between subsidies and subsidies elimination.

\subsection{City transportation and subsidies}

$\mathrm{H}_{0}$ : There is no meaningful relationship between City transportation and subsidies elimination.

$\mathrm{H}_{1}$ : There is a meaningful relationship between City transportation and subsidies elimination.

\subsection{Tuition fee and subsidies}

$\mathrm{H}_{0}$ : There is no meaningful relationship between tuition fee and subsidies elimination.

$\mathrm{H}_{1}$ : There is a meaningful relationship between tuition fee and subsidies elimination.

\subsection{Consumer consumption and subsidies}

$\mathrm{H}_{0}$ : There is no meaningful relationship between consumer consumption and subsidies elimination.

$\mathrm{H}_{1}$ : There is a meaningful relationship between consumer consumption and subsidies elimination.

\section{The results}

In this section, we present details of our survey on testing five hypotheses using Pearson correlation test ratio. Table 1 shows details of our survey on all five hypotheses. 
Table 1

The results of Pearson test result

\begin{tabular}{lccl}
\hline Hypothesis & Pearson ratio & P-value & Result \\
\hline Unemployment and subsidies & 0.568 & 0.000 & $\mathrm{H}_{0}$ rejected \\
Inflation and subsidies & 0.062 & 0.716 & $\mathrm{H}_{0}$ accepted \\
City transportation and subsidies & 0.363 & 0.027 & $\mathrm{H}_{0}$ rejected \\
Tuition fee and subsidies & 0.122 & 0.472 & $\mathrm{H}_{0}$ accepted \\
Consumer consumption and subsidies & 0.615 & 0.000 & $\mathrm{H}_{0}$ rejected \\
\hline
\end{tabular}

As we can observe from the results of Table 1, the null hypothesis for the relationship between unemployment and subsidies is rejected when the level of significance is one percent and it means that our survey students strongly believed that the recent change on subsidies could lead to higher rates of unemployment. The second hypothesis, however, is accepted and, apparently, our surveyed students did not believe the recent deregulation had any impact on inflation. The third hypothesis is associated with the relationship between city transportation and subsidies and as we can observe from the Pearson ratio obtained from Table 1, the null hypothesis can be rejected when the level of significance is five percent, which means that deregulation on subsidies has helped city transportation. The fourth hypothesis was associated with the relationship between tuition fee and subsidies and our survey has confirmed that there was no relationship between these two items. Finally, the last hypothesis is associated with relationship between consumer consumption and subsidies and the null hypothesis is rejected when the level of significance is five or even one percent. In other words, our survey people believed that deregulation has created the opportunity to reduce consumers' pattern especially on energy sector.

\section{Conclusion}

In this paper, we have surveyed the impact of recent changes on food and energy prices on different maco and microeconomic terms including inflation, unemployment, consumer consumption, tuition fees and public transportation. The survey designed and distributed a questionnaire in Likert scale among 51 undergraduate and graduate students attending in different fields of economy, social science, management and psychology. The survey has analyzed the data using Pearson correlation test and based on the survey, we have realized that two hypotheses associated with unemployment and consumer consumption can be rejected when the level of significance was one percent, while one hypothesis associated with city transportation was rejected when the level of significance was five percent. The survey, however, did not find enough evidence to believe that there were some relationships between removing subsidies and inflation as well as tuition fees.

\section{Acknowledgment}

The authors would like to thank the anonymous referees for their constructive comments on earlier version of this paper.

\section{References}

Badcock, J., \& Lenzen, M. (2010). Subsidies for electricity-generating technologies: A review. Energy Policy, 38(9), 5038-5047.

Blanes, J.V., \& Busom, I. (2004). Who participates in R\&D subsidy programs?: The case of Spanish manufacturing firms. Research Policy, 33(10), 1459-1476

Gilbert, A. (2012). Housing subsidies in the developing world. International Encyclopedia of Housing and Home, 638-643. 
Gupta, S., \& Mukherjee, A. (2012). Utilization of passenger transport subsidy in Kolkata: A case study of Calcutta State Transport Corporation. Research in Transportation Economics, In Press, Corrected Proof.

Hao, J., Zhao, W., Huang, H., \& Guan, H. (2009). Calculating model of urban public transit subsidy. Journal of Transportation Systems Engineering and Information Technology, 9(2), 11-16.

Karami, A., Esmaeili, A., \& Najafi, B. (2012). Assessing effects of alternative food subsidy reform in Iran. Journal of Policy Modeling, 34(5), 788-799.

Kleer, R. (2010). Government R\&D subsidies as a signal for private investors. Research Policy, 39(10), 1361-1374

Lin, B., \& Jiang, Z. (2011). Estimates of energy subsidies in China and impact of energy subsidy reform. Energy Economics, 33(2), 273-283.

Liu, W., \& Li, H. (2011). Improving energy consumption structure: A comprehensive assessment of fossil energy subsidies reform in China. Energy Policy, 39(7), 4134-4143.

Obeng, K., \& Sakano, R. (2008). Public transit subsidies, output effect and total factor productivity. Research in Transportation Economics, 23(1), 85-98

Sadeghi, M., \& Ameli, A. (2012). An AHP decision making model for optimal allocation of energy subsidy among socio-economic subsectors in Iran. Energy Policy, 45, 24-32.

Shin, I., \& Kim, H. (2010).The effect of subsidy policies on the product quality improvement. Economic Modelling, 27(3), 687-696 